Luis Burgos Fuentes

\title{
Perfil y hazaña de don Enrique Molina
}

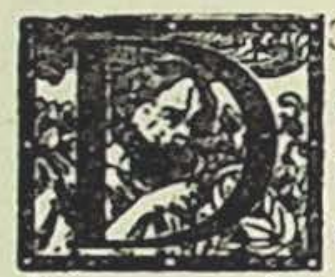

ON ENRIQUE, como sin más se le llama en su barbacana penquista, ha terminadõ su quehacer público y retirádose a su hogar doméstico, mal traído por quebrantos de salud. La vida resiste en él y con ella ese epicúreo don que la domina: búsqueda de la "felicidad" mediante nobles afanes.

"Atenea”, en gesto reflejo, vuélvese sobre la persona de su creador, sustentador e inspirador para ponderar su vida y su obra, enalteciéndola.

La peripecia de su existencia ha quedado puntualmente descrita en la obra que le consagró el escritor peruano Armando Bazán y que llamó Vida y obra dol maestro Enrique Molina (Nascimento, Santiago de Chile, 1954).

Nació el 4 de agosto de 1871, en La Serena.

Fueron sus padres, don Telésforo, "dedicado a las actividades de la escribanía", "hombre de energía desbordante, que encuentra su placer en la repetida conquista femenina y en la dilapidación de lo que gana más o menos fácilmente en el ejercicio de su profesión", y doña Mercedes, que había de perecer cuando su hijo contaba sólo 
cuatro años de edad. Estirpe castellano-vasca de que el descendiente parece heredar, por la vía paterna, una joie de vivre inmarcesible y una fuente de juvencia milagrosa y, por la vía materna, una voluntad tenaz de conservación e incremento del patrimonio espiritual y una necesidad de decoro, de lo que resulta una personalidad singu. lar, benedictina de la cultura en su doble faz teórica y práctica y, al mismo tiempo, gozosa y pánica. La lograda síntesis muestra, de lejos, la figura relevante del "maestro" indefectible y, de cerca, la humanísima de un señor perennemente joven.

Estudió las primeras letras en la "Escuela Pública de Niñas" que, en su ciudad natal, dirigía doña Juana Nepomucena Lobos, "Ita" para sus alumnos, a la que concurrían las muchachas de las mejores familias y, también, algunos muchachitos seleccionados. La escuela destartalada y destituida de recursos materiales, hacía las veces, por su prestigio pedagógico, de liceo fiscal.

"Pero mi llegada a ella - dice don Enrique- fue como la llegada a un oasis para quien ha vagado sufriente y desorientado por desiertas y secas soledades. Obraban el milagro almas femeninas, abnegadas, afectuosas y comprensivas.

"Mi sección estaba a cargo de misiá Pepita, niña de mediana estatura, más bien delgada, de movimientos ágiles y ligeros, muy simpática y sumamente bondadosa. ¡Cuánto la queríamos sus alumnos!

"Un día nos anunciaron que no vendría más, porque se había entrado de monja. Tuvimos una gran pena y todos la lloramos. Lágrimas de niños, prontas para brotar y prontas para secarse, pero lágrimas al fin".

El cuadrito, redivivo en la conciencia del octogenario, muestra la finura de su sensibilidad y su especial percepción y apetición de lo femenino. Misiá Pepita está vista en su figura física y en su figura espiritual y consentida dramática y tragediosamente en su perdimiento para la vida mundana al ocluirse en la concavidad claustral. Y consignada la reacción de los pequeños escolares súbita y transitiva a un mismo tiempo. ¿Concederá don Enrique más largo duelo al 
desvanecerse sucesivo de las figuras femeninas que han de constituir su reiterado encantamiento en la larga senda de su vivir?

Veamos ahora su encuentro con la varonía en la misma función docente. "Mi profesor - de preparatoria- no manifestaba ningún afecto por sus alumnos y parecía al contrario complacerse en atemorizarlos y hasta martirizarlos. Usaba patilla redonda y un gesto habitual suyo era llevársela con la mano derecha a la boca, para chupársela.

"Con frecuencia, aplicaba el castigo de poner de rodillas - por lo demás corriente en aquel tiempo- ya fuera en la sala de clases o afuera, en el corredor inmediato, $\mathrm{y}$, agachándose un poco, como $\mathrm{e}$ ! animal que acecha su presa, mordiéndose la patilla, miraba con fruición sádica a los castigados".

Don Enrique, ya hombre y maestro, reiterará la doctrina del amor vivo como substancia del quehacer educacional y la hará realidad en el ejercicio de su profesión. El doble cuadro de su experiencia infantil, en luz y sombra, igualmente vívidas, muestra cuánto de esta doctrina arranca de su sensibilidad personal, de su ethos.

El adolescente se incorpora al liceo.

Hallará que, para ser humanístico, les falta el latín y el griego. $\mathrm{Y}$ añadirá que griego en los liceos chilenos nunca lo hubo y que el latín desapareció "por obra de los pujos progresistas de algunos dirigentes, entre los que no faltaban ilustres hombres de letras como don Augusto Orrego Luco y don Benjamín Vicuña Mackenaa que más tarde manifestaron arrepentimiento de lo que habían hecho". Don Enrique mismo se contó siempre entre esos progresistas que tuvieron por buena la supresión del latín y el advenimiento de las lenguas modernas en su reemplazo, más aptas para la introducción en la cultura del tiempo actual. El latín fue repudiado por "muerto" aunque sigue siendo y no dejará de ser la raíz muy viva de nuestra lengua castellana. En verdad, se le suprimió por estar demasiado vinculado a la faena de los eclesiásticos, cuyo largo imperio se deseaba postergar. 
El escolar Enrique Molina estudió tres idiomas: francés, inglés y alemán, aunque estaba obligado a estudiar sólo dos. Distinguióse en su cultivo, según el parecer de sus maestros. Pero salió del liceo sin manejarlos siquiera pasivamente, es decir, para el solo efecto de traducirlos.

Más tarde, con reiterados esfuerzos suplió esta deficiencia. Y de hecho, leyó en tres idiomas extranjeros.

El liceo que conoció don Enrique había sufrido ya la influencia de las tendencias innovadoras y añadido a su tradicional tronco humanístico la rama de las Ciencias. Físicas, que constituyen el llamado "humanismo científico" (Física, Química, Cosmografía, etc.). Había sido el excepcional logro de la batalla librada por don Diego Barros Arana contra el imperio de la tradición puramente letrada, en su rectorado del Instituto Nacional (1863-1872). Todo elio seguía estudiándose "ejercitando especialmente la memoria y, en forma reducida, la reflexión y la actividad propiamente tal de los educandos".

Este adolescente fue gran lector. ¿Qué leyó? ¿A dónde lo llevaron sus preferencias o el azar de las oportunidades? Leyó Don Quijote y el Gil Blas de Santillana, Ivanhoe y Los viajes de Gulliver, Pablo y Virginia y Los tres mosqueteros, una breve Historia de Carlo Magno y de los Doce Pares de Francia y, finalmente, Martín Rivas y Aritmética en el Amor. En resumen, la gallarda aventura heroica y la gentil aventura erótica se infiltraban en su alma en la hora de las "fundaciones".

Tal la experiencia sistemática de la cultura adquirida en las aulas liceanas. Pero, ¿qué estímulos prevalecían en el mundo de su tiempo?

Don Enrique viene al mundo en esa época de la historia de Chile que se ha llamado de la "República Liberal", momento de expansión de reprimidas tendencias libertarizs, que los severos fundadores de la república "en forma" del período precedente habían tenido en jaque. La juventud de la época se enardecía con las perspectivas de un mundo más amplio y más flexible: sentíanse "revolucionarios” en política y, como es natural, románticos en literatura.

Los instrumentos de la economía y los instrumentos de la cul- 
tura se ensanchaban al mismo tiempo que las formas institucionales políticas incorporaban amplios sectores populares al poder público: el ferrocarril longitudinal llegaba hasta la frontera; la Universidad de Chile sentaba sus reales en el palacio que labró Toesca en la "Alameda de las Delicias" y que aún hoy ocupa la "Casa Central" y la gran multitud de los sin dinero tenían acceso a la ciudadanía activa con derecho de sufragio por la sola virtud de saber "leer y escribir". Por otra parte y en virtud de la misma tendencia libertadora se luchaba contra el imperio de la Iglesia y frente a la Iglesia enseñante se alzaba el Estado docente, es decir, cambiaba de patrón el timón de la nave y las generaciones venideras serían bautizadas en el reino del Espíritu sin la bendición divina aunque siempre bajo el signo de la Patria, representada por el Estado. Ese mismo Estado pretendía ejercer las funciones tutelares de contar los miembros de la grey al nacer y registrarlos laica y públicamente y disponer para ellos cn la hora de su muerte públicos y laicos lugares de último reposo. Todo ello para evitar la disensión y la discriminación de los que vivían bajo el signo de la Iglesia - tan numerosos- frente a los que vivían fuera de ese signo - que comenzaban a ser legión. Y, en último término, para arrancar de las manos de la Iglesia un poder espiritual de sugestión tan grande como es el de recibir y despedir al ser humano en las horas del nacer y del morir, símbolos de un supremo poder. Y el poder de autorizar los matrimonios bajo simples fórmulas contractuales en lugar de hacerlo bajo la forma solemnísima, pero rigurosa y restringida, del sacramento eclesiástico.

Estos aires de libertad, aires de fronda, embriagaron el alma del adolescente Enrique Molina y a ellos permaneció fiel durante su vida entera.

Finalmente, vino la guerra: Chile, por segunda vez en el curso de su historia enfrenta a los dos Estados vecinos, más extensos, ricos y poblados $y$, por segunda vez, los vence después de heroicas batallas por tierra y por mar.

A las apasionadas batallas políticas internas, aún pacíficas, se unen las batallas políticas internacionales por la espada y el fuego. 
El niño Enrique Molina se despide así de su infancia y entra en la adolescencia bajo un complejo de estímulos decisivos de amor a la Patria, bajo los signos de la libertad política creciente y de creciente autonomía nacional. Finalmente la guerra ha traído la riqueza pública: las salitreras llenan las arcas fiscales y la nación se dispone a convertir esos valores económicos en fuerza de expansión para la etapa de crecimiento venidero en el campo industrial, para lo cual previamente ensancha y fortalece sus sistemas educacionales.

Entretanto el adolescente Enrique Molina se dispone a entrat a la Universidad para convertirse en profesional.

Don Telésforo lo sueña médico. Pero la cortedad de los recursos económicos frente a lo exorbitante de las expensas escolares en esa especialidad, disuaden al candidato. ¿Era muy fuerte en ese sentido su vocación? ¿O era más bien el señuelo del porvenir brillante que la carrera en sí parecía ofrecer? Convierte su ideal: ya no será médico sino abogado. Es una conversión exenta de fe: es un mero hecho, es la desorientación...

El apuesto galán que entonces ya era, paseó su tedio por lugares públicos y se hizo muy diestro jugador de billar... Y junto al tapete verde que señoreaba, encontró su destino. Alguien le habló de la nueva escuela universitaria y del nuevo destino ofrecido con muchas instancias por el gobierno a la juventud. "Tendréis todas las facilidades necesarias, decían los panfletos del "enganche": alimento, instrucción gratuitos. $\mathrm{Y}$ veinticinco pesos mensuales de sueldo. ¡Además dispondréis de pasajes para ir a vuestros puntos de origen en los períodos de vacaciones!" Se trataba de enrolar candidatos a la docencia pública en colegios del Estado y en la rama de la educación colegial o secundaria o humanista.

Al recordar ese momento decisivo de su existencia hace en Confesión personal un balance de lo vivido en las escuelas en que se ha formado: "Fui en verdad un liceano con muchas distinciones en mis exámenes. Pero salí del liceo muy ignorante, sin disciplina y sin hábitos de trabajo. ¡Ah, el liceo de entonces, $\mathrm{mi}$ recordado liceo! No faltaban en él profesores dignos, abnegados y competentes. Pero 
su atmósfera general estaba más bien algo desmoralizada y era desmoralizante".

\section{Y luego:}

"Los dos años y medio que pasé en seguida en la Escuela de Derecho de esta Universidad - la de Chile- no obstante el recuerdo lleno de admiración y afecto que conservo por algunos de mis maestros, no fueron adecuados para curarme de mi falta de voluntad y relajación de carácter. Las clases eran pocas y las exigencias pocas también".

En resumen, un alma insatisfecha en que la generosidad insta a la expresión de cordiales afectos y la crítica racional a la confesión desengañada de desvalores.

"Ofreciéndoseme la posibilidad de ejercicio de dos profesiones, la de abogado y la de profesor, tenía que optar entre varios caminos. La simultaneidad conduciría a la mal atención de ambas actividades. O a hacer del profesorado una especie de salvavidas económico para los primeros procelosos tiempos de la abogacía.

"El pensamiento de que Chile necesitaba profesores y de que abogados no le hacían falta, selló mi decisión. Sería sólo profesor".

El joven Enrique Molina se había hecho hombre. Ha sellado su destino y no por razones subalternas sino por altos principios de solidaridad social.

"El Instituto Pedagógico abrió sus puertas en agosto de 1889 en una vieja casona de la llamada hasta hace poco "Alameda de las Delicias”. En el Pedagógico aprendí a trabajar, a estudiar y empecé a seguir el seguro resorte de una disciplina interior". "Aquí aprendí a dar importancia al carácter y a trabajar con disciplina. Se me abrieron en aquella sazón perspectivas de la cultura y de la vida nacional de que antes no tuviera idea". Los profesores alemanes que fundaron el "Instituto Pedagógico" satisficieron la necesidad intelectual de un saber calificado y la necesidad moral de una disciplina superior de la vida del espíritu. Así cuando ya profesor pone término a sus estudios de Derecho - por no dejar cabo sin atar-, en 1902, halló "entre sus amigos magistrados y abogados de gran situación que, 
interesándose por su porvenir, lo exhortaban a que fuera abogado y le ofrecían ayuda para darle trabajo. "Significaba eso - confiesa- presentarme perspectivas muy tentadoras. Pero no me aparté de lo que había resuelto". Su concepción superior de la vida del espíritu, su firme convicción de que al obrar conforme a su vocación, obraba también, por eso mismo al servicio de la patria, pudo apartarlo de brillantes señuelos de prosperidad y nombradía ciertas. Por eso, podríamos decir que en 1892 no se tituló de profesor del Estado sino que se "ordenó" de profesor del Estado.

En cambio, para concluir del todo la etapa de la preparación y hacerse a plena mar de la vida, apenas concluidas las faenas académicas, contrae matrimonio con la dama chillaneja doña Ester Barañao, 1903. Chillán, donde se estrenó como profesor de historia, le permitió terminar los "años de aprendizaje" académico y vital; le dio dama de calidad por mujer y compañera digna de su vida por venir y le dio, además, un grande amigo, en cuya compañía habría de hacer las primeras jornadas heroicas de su carrera docente y cuyo triste fin lo ha llenado de melancolía, en cuanto tal modalidad quepa en su sonriente y "meliorista" forna de vida.

"El núcleo capital de sus labores espirituales - dice Claudio Rosales - lo constituye - durante su época chillaneja- la historia concebida como disciplina científica. Y siguiendo a Seignobos y siguiendo a Altamira dio a su enseñanza las modalidades que esos sabios maestros han generalizado por los cuatro ámbitos del globo. De su cátedra fueron desterrados los viejos textos de Duruy, que no son más que un trasunto del anecdotario historial de Heródoto en lo referente a la historia de los pueblos orientales".

Por el volumen de su ićeario la cátedra se le hizo estrecha y debió buscar sitiales más empinados para hacerse oir a más largas distancias. Concurrió al Congreso General de Enseñanza Pública de 1902 y al 4. ${ }^{\circ}$ Congreso Científico Panamericano de 1908. En ellos dio a conocer el resultado de sus meditaciones sobre la Metodología de la Historia y tocó entre otros asuntos el problema de la interpretación de las fuentes históricas transmitidas por la tradición. 
La actitud suya frente a los mitos es digna de consideración, porque coincide con el incremento de inusitado que tuvieron en Europa, a principios de este siglo, los estudios relativos a las leyendas mitológicas. En efecto, en 1906 el sabio alemán Gruppe publicó su monumental Historia, Mitología e Historia de las Réligiones; en 19071911, Reinach su Manual de Filología en que toca el problema de la interpretación de los mitos. Al mismo tiempo se formó en Alemania una sociedad para estudiar la mitología desde el punto de vista comparativo. Lo que pone de manifiesto la importancia que, para los hombres de ciencia de ese tiempo, tuvieron estos problemas. Wundt, Levy Brühl, Durkheim, como psicólogos, sociólogos y moralistas, se preocuparon también de ellos. Estos nombres sirven para mostrar cómo el señor Molina, desde los primeros tiempos de su carrera, regulaba su inquietud espiritual al ritmo del progreso científico europeo.

El profesor de historia, don Enrique Molina, era también Inspector General en el Liceo de Chillán. ¿Con qué criterio afronta el señor Inspector General los problemas de educación que son de su estricta competencia, en ese liceo y en aquel entonces?

El -que tan vivamente se ocupa de sí mismo y que se autohistoria - nos lo dirá: "Una idea determinista, no definida aún pero clara como intuición, me sirvió mucho, tanto en mis clases como fuera de ellas en mis funciones de Inspector General.

"Cuando los veía incapaces o desordenados, a veces molestos, me decía en mi interior: "Pobres muchachos, no tienen la culpa de ser como son. Lo han heredado. El Destino los ha hecho así.

"Por supuesto que esta reflexión inspiradora de un proceder humano, tolerante y paternal con ellos, me la guardaba para mí mismo. Y a ellos trataba de despertarles sólo el sentimiento de su responsabilidad.

"No cabe señalar contradicción en esta noble manera -añade en seguida- La vida del espíritu es creación sobre los elementos biológicos que forman la urdimbre básica del individuo".

¿Qué leía entretanto? 
"Entre las lecturas sólidas que llevé a cabo en aquel tiempo, debo recordar la Antropología de Taylor y la Descendencia del hombre de Darwin, libros que influyeron poderosamente en formarme un criterio positivista y evolucionista para la interpretación de los fenómenos biológicos y sociales.

"En el orden pedagógico leí La cducación intelectual, moral y física, de Spencer, la Ciencia de la educación, de Alejandro Bain, y la Enseñanza de la historia, de Rafael Altamira.

"La obra de Spencer es admirable por su claridad y sencillez y por la naturalidad con que se desenvuelven sus concepciones. La idea spenceriana de fundar la educación moral sobre todo en hacer sentir las consecuencias de los propios actos, no deben olvidarla nunca ni los padres ni los educadores, siempre - se entiende- que las consezuencias no vayan a traer consecuencias irreparables".

Tal es el panorama de sus años iniciales de profesor: inspira su enseñanza en los tratadistas de mayor autoridad de su tiempo en el ramo de historia; y su función educadora en los principios de la Ciencia Positiva y de la Teoría de la Evolución. Las teorías de Comte, Darwin y Spencer, definen su postura.

Con todo, en ese Congreso de Educación de 1902, don Enrique Molina se alista entre los defensores del intelectualismo o, para decirlo con mayor exactitud, entre los defensores de la educación general como algo previo a la educación especial o, para expresarlo todavía con una tercera fórmula, entre los que sustentan que es preciso formar primero al "hombre" y después al "profesional".

El desarrollo del industrialismo y del capitalismo avasallador había suscitado en Francia agudas críticas contra el sistema educacional del país que parecía a los observadores excesivamente preocupado de generalidades y despreocupado de la lucha concreta por el predominio industrial, base del predominio económico y, en fin, de la subsistencia nacional. Fue la doctrina de Demolins, alarmado ante la "inmensa superioridad social, política, comercial, industrial, financiera y moral de la raza anglosajona" frente al virtuosismo inoperante de los letrados franceses. La obra, traducida al español, se aplica- 
ba con mayor rigor a la nación española. Y conocida en Chile inspira a los defensores de la corriente economista.

Don Enrique Molina ve en ese punto de vista un error de perspectiva. Por eso, sostiene en el Congreso de Educación de 1902, que la tesis de Demolins, valedera acaso para naciones europeas de milenaria tradición cultural no lo era en Chile, país sin tradición de cultura, y que lo que allá es exceso es aquí defecto y, en consecuencia, lo que allá requiere poda, merecería aquí fomento. En resumen, piensa que en nuestra nación mestiza, conviene por sobre todo afirmar la primacía del espíritu mediante una sostenida labor sistemática de escuela, so peligro de naufragio cultural.

Mirado en conjunto este período muestra al joven profesor resuelto a realizar el ideal concebido en el Instituto Pedagógico: desterrar una docencia rutinaria y retardataria para substituirla por una pedagogía fundada sólidamente en rigurosa y actualísima cultura; en virtud de ello lo vemos asumir la posición más avanzada en aquellos días: la triunfante posición de la ciencia positivista que, respecto del problema del hombre, para en la doctrina de la Evolución, vinculándolo a la serie de las especies animales, que en él culmina; y en materia de Pedagogía, se identifica con las concepciones utilitarias de Spencer, de que el profesor Molina se enamora, especialmente en lo relativo a la Educación Moral.

Si se considera lo que esta posición excluye, se advertirá que ello se refiere a las concepciones extrarracionales en que se funda la religión y también a las concepciones puramente metafísicas, meramente especulativas de que el positivismo había hecho tan decisivo repudio.

$\mathrm{Y}$, sin embargo, en el orden educacional y frente a la realidad chilena, don Enrique Molina sentía que lo esencial era vincularse cada vez con más firmeza en este mundo del pensamiento que nunca nos ha pertenecido, al que somos advenedizos y que en esta actitud consistía el verdadero realismo, oponiéndose a las tendencias pragmatistas que querrían llevar rápidamente al educando a las destrezas de la actividad económica. 
El Rector Molina.-Actúa como profesor durante dos años en el Liceo de Concepción: 1903-1905.

Pero en ese año, se produce una situación de grave crisis en el Liceo de Hombres de Talca y el gobierno echa mano de una figura de primera importancia para confiarle la misión pacificadora y restauradora de ese establecimiento venido muy a menos.

El eminente geógrafo don Gonzalo Cruz había regido el establecimiento con adversa fortuna. El sistema disciplinario extremado había acabado por suscitar una revuelta de los estudiantes con violencias en las personas y en las cosas y vergonzosa intervención de la policía. Había una grave crisis de organización y una grave crisis de autoridad.

Don Enrique Molina aplaca la borrasca estudiantil con sus armas pedagógicas: la comprensión, la tolerancia de una parte, hijas del amor a la juventud; de otra, la sostenida instancia a la recuperación de los valores mediante el alto y personal ejemplo de abnegación y fervor en el trabajo y la subida ley de sus propios valores.

$\mathrm{Se}$ impone. Estudiantes de esa época el novelista Mariano Latorre, el crítico Armando Donoso y el poeta Armando Meza Fuentes, todos a una, testimonian la prodigiosa recuperación moral de ese alumnado bajo la dirección del Rector Molina.

Más duro de lograr fue con el profesorado.

El Rector Molina de la primera generación de profesores del Estado egresados del Instituto Pedagógico y promotores de la $\mathrm{Re}$ forma de los Estudios Secundarios llamada de 1892 en que se organizaba los estudios según el Sistema Concéntrico, tenía que actuar conforme a normas científicas y, según hemos visto, conforme a criterios harto modernos para esos días. El profesorado de Talca era de otra edad mental, de otra atmósfera espiritual. Debían parecer al nuevo-Rector precisamente reaccionarios en todo orden de cosas: en el tipo de saber en que se fundaban y en el tipo de transferencia de conocimientos que empleaban.

A la inversa, esos profesores tenían que ver en el nuevo Rector una verdadera plaga, un vendaval revolucionario de fondo y forma. 
Armando Bazán, historiando este momento, declara que, mientras en una sala de clases un profesor doctrinaba a los alumnos en las doctrinas de Copérnico, en la sala vecina otro profesor les contaba cómo Josué ordenaba al Sol y a la Luna que detuvieran su carrera en el cielo hasta que él hubiera concluido la faena, impuesta por Dios mismo, de tomar la plaza de Jericó. Y cómo aquellos obedientes astros, en efecto, se paraban.

Los profesores estaban sostenidos por la ciudad, cuyo espíritu representaban. El Rector y sus seguidores, por el Consejo de Instrucción Pública, cuya política habían venido a establecer.

Así poco a poco los profesores más señalados por su espíritu de contraposición airada y tenaz al Rector, fueron saliendo a promociones diversas. Y la dura batalla fue ganada.

En medio de esos afanes ardidos, el Rector comentaba los primeros pensadores que había comenzado a frecuentar: Lester Ward, el meliorista, y William James, el pragmatista. Era en 1906.

Entretanto su grande amigo el profesor de francés, Alejandro Venegas, a quien había hecho venir de Chillán para que estuviera a su lado, en calidad de vicerrector, se orientaba, cada vez con mayor pasión, en los problemas políticos de la nación. Tenía la impresión de que Chile decaía y de que sus gobernantes eran ciegos y sordos a los males y clamores que la situación originaba. Veía la clave del descalabro en la errada política económica. Y el móvil de esa política en la influencia de la oligarquía de los terratenientes.

Ambos publicaban.

Ward.-Es un sabio - dice el propio don Enrique- del siglo XIX, de formación positivista y evolucionista y de concepciones psicológicas y sociales muy amplias.

"Sus ideas ejercieron sobre mí mucha influencia, en especial dos de sus tesis: la del meliorismo, actitud activista, término medio entre el optimismo y el pesimismo en que Ward hace suya la divisa de Stuart Mill cuando dice: “¿A qué hemos venido al mundo? A dejarlo un poco mejor de como lo hemos encontrado". 
"La otra tesis de Ward a que me he referido, es la de la sociocracia, o sea, aquella en que preconiza una organización colectiva en que, limitando y poniendo atajo a las pretensiones y rapacidades individuales, predominen los intereses sociales".

Invitado por el Rector don Valentín Letelier leyó su conferencia en la Universidad de Chile en 1907. "Mi conferencia sobre Ward significó una de las primeras publicaciones teñidas de socialismo que han aparecido en Chile".

James.-El estudio sobre James constituía un trabajo destinado al Congreso Científico Panamericano de 1908, en que, finalmente, no se leyó. Fue dado a conocer como conferencia en la Universidad de Chile, 1908.

"Para el pragmatismo no hay verdad objetiva, no hay verdad en sí; son verdaderas la representación y la idea que sirven para la acción. Puntos de vista que yo no compartía y criticaba en mi ensayo, por considerarlos formas de escepticismo.

"Sin embargo, cuánta rica aplicación pueden tener en el campo de la creencia. A nadie le es dado afirmar con certidumbre que exista para el hombre una vida de ultratumba; pero nadie puede afirmar tampoco que no exista. Con modestia y humildad intelectual podemos tomar ante este misterio una actitud pragmatista y con recogimiento hundirnos en la búsqueda del mejor camino' para nuestra actividad, para sacar del fondo del ser nuestra realidad espiritual".

La conferencia sobre Ward escandalizó un poco por su aire socialista. La que versaba sobre James le costó un desaire del Rector subrogante de la Universidad. "El buen señor pertenecía seguramente a esa generación de hombres progresistas de nuestro país que en los años del siglo pasado entre el 60 y el 90, creían que el positivismo significaba el ápice definitivo del pensamiento humano, más allá del cual no había que buscar nada ni inquietarse por nada en materia de temas trascendentales. Ignoraba la existencia de James y la de Bergson y Eucken también, por supuesto, y no sospechaba que la 
Metafísica, condenada por el positivismo a relegación perpetua, renacía lozanamente en las preocupaciones del espíritu".

Por el mismo tiempo, Venegas publicaba La Procesión de Corpus en que, bajo formas literarias, expresaba su estado de ánimo abatido por derrotas amorosas. Y luego, sublimando su derrota erótica, se lanzaba por la vía de la redención social con dos obras epistolares: Cartas al Excelentísimo Señor don Pedro Montt sobre la crisis moral de Chile en sus relaciones con el problema económico de la conversión metálica, firmado por el "Dr. Valdés Cange", 1909, y desoído este llamado, reiteraba con mayor fuerza su pensamiento en Sinceridad. Chile íntimo en 1910, destinada al Presidente electo, don Ramón Barros Luco. Esta obra provocó extremado escándalo y el ostracismo del autor, repudiado por sus adversarios como antipatriota a causa de la energía de sus críticas a las instituciones nacionales. $Y$ en definitiva su derrota moral y su exclusión del profesorado, ocurrida en 1914.

"Me parece que Sinceridad ocupa un lugar único en la literatura chilena", dice don Enrique. Y añade: "Escrito en el Liceo de Talca, oasis de tranquilidad en medio de un ambiente adverso, en un cuarto sencillo que bien ha merecido los honores de celda de un anacoreta, el libro recién comentado, fuera de los valores ya mostrados en él, es un documento de importancia fundamental para la vida de Chile en los primeros años del presente siglo".

Ambos amigos procuraban reformar el país. Molina por la vía de las lentas evoluciones que derivan de cambios de altura espiritual de las gentes, Venegas por la acción directa. Molina cosechaba en la hora adversa desaires, desdenes. Venegas, primero silencio y luego una tempestad desatada contra la que acabó por ser impotente.

Molina fue enviado al extranjero como premio a la distinción lograda en el cultivo de altas disciplinas en 1911 y dejó a su amigo en lo más apretado del conflicto.

Viaje de estudio a Alemania.-El profesor - ahora de cuarenta años- visita la tierra patria de sus propios profesores del Instituto 
Pedagógico. Y la halla en la cima de su poder total: cultura y civilización magníficas y espléndidas, envidiable y envidiada. Hamburgo, el puerto colosal, mitad sobre las aguas, mitad sobre tierra firme - como anota Bazán-, con sus bosques de chimeneas de barcos por un lado y sus bosques de chimeneas de fábricas por el otro; y luego Berlín, la ciudad monumental asentada en una planicie de pinares y de lagos, pulquérrima; y más tarde Nüremberg con sus estampas de castillos y palacios medievales, con las torres góticas de sus templos, configuran esta tierra de encrucijada en el corazón de Europa, que la más laboriosa y la más profunda nación de Occidente ha llevado cn ese momento al cenit de su potencia.

En ella la pedagogía, "desenvolvimiento de toda perfección que en sí lleva la naturaleza del hombre" - conforme al concepto kantiano-, adquiere pluralidad de formas y sentidos. Es también un campo de exploración inmenso. Visita la Universidad de Münich, los gimnasios de Berlín y las escuelas de los pequeños pueblos en que suelen prepararse los futuros capitanes de industria o de la guerra - los señores de la tierra. Así Fulda, cuyos maestros y escolares, en tenida de excursión perpetua, aprenden en el contacto inmediato con la naturaleza; mientras Wetekamp en su "Real Gimnasio Werner Siemen" lo induce a "formar ante todo en el alumno, por medio de su propia actividad, la aptitud para el trabajo, de suerte que llegue a ser un hombre laborioso con originalidad".

Ese proceso de desformalización de la enseñanza - nota esencial de esas diversas actitudes - busca la renovada fuente de vigor en la postura inicial del hombre frente al mundo de las cosas cuyo dominio es su destino o en la disciplina efectiva del trabajo creador. Y reclama entera libertad para la faena creadora, con repudio cabal de programas y reglamentos inhil:tores, según postulan Paulsen y Munch.

Mientras el profesor Molina pasea y aprende, Venegas se debate en Talca en la encrucijada, repudiado por colegas cuyo patriotismo en conserva ha magullado y por escolares prestos a abanderizarse en los grupos beligerantes. 
El Rector torna a su sede y su acrecido prestigio sumado a su don personal de seducción, acarrea la paz. Venegas, vencido, se exonera de la función docente en 1914 y Molina, triunfador, es promo. vido en 1915 al rectorado del Liceo de Hombres de Concepción.

Rectoría del Liceo de Hombres y fragua de la Universidad de Concepción.-El hombre de la fortuna propicia, del alto don de seducción humana y el gran dirigente que es Enrique Molina, llega, por fin, a Concepción, que ha sido para él sede olímpica.

Ha sido llamado para dirigir el Liceo de Hombres. Y lo dirige con la habitual competencia y dignidad. Pero es la aventura de la creación de una Universidad la que embarga su ánimo y acapara las miradas del observador durante este período de su vida. Y la Universidad, una vez creada, el Rector del Liceo de Hombres se convierte en Presidente del nuevo Instituto y al mismo tiempo en su Rector.

¿Cuáles fueron las altas realizaciones del Rector Molina en el Liceo de Concepción, organismo entonces ya nonagenario?

Recibía un palacio que se acababa de construir y que estaba dotado de los muebles de todo orden que un tal establecimiento ha menester: biblioteca, laboratorios, salas de dibujo y de trabajos manuales, magníficos, distribuidos en tres pisos de un monumento arquitectónico.

Recibía, además, un viejo internado, instalado en un venerable edificio construido hacia la segunda mitad del siglo pasado, en cuya recia planta, fabricada de adobes, ni siquiera faltaba la "Capilla" para los oficios religiosos que había dejado de usarse durante décadas.

Recibía aún tradición cultural de alta docencia ejercitada durante nueve décadas e irradiada a la ciudad por personalidades relevantes con que la ciudad se había identificado. Era una herencia grave y comprometedora.

Pero la singular prestancia personal, intelectual y moral del nuevo Rector se bastó a satisfacer ese vacío moral con creces.

Conservó el alto nivel del profesorado, la disciplina del numerosísimo alumnado - que llegaba al millar de estudiantes- median- 
te el imperio de la sugestión espiritual, impulsó con singular brillo la extensión cultural, convirtió el liceo en sede de bachillerato, la primera en el país que funcionaba fuera de la capital -1917- y, fiel a su sentido jocundo de la vida, impulsó y realizó la institución de las "Fiestas de la Primavera", que conmovieron y deleitaron a la sociedad penquista.

Al caer las tardes, en esa hora vesperal propicia al solaz del espíritu, abríanse grandes y venerables portones de la calle Caupolicán por los cuales iban penetrando damas y caballeros, ceremoniosamente, en un gran patio cubierto de flores y animado por un surtidor central y encuadrado por claustros severos y arrumbaban a la sala de actos, alba, luminosa y digna. El Rector los aguardaba para recibirlos y saludarlos con algunos profesores y su cuerpo administrativo. $\mathrm{Y}$ ya instalados, la masa de estudiantes ocupaba los asientos postreros.

Y ocupaban la cátedra personalidades de alto vuelo, en ocasiones venidas del prestigiosísimo Santiago con relevantes títulos de personal excelencia en las ciencias o en las artes. Ahí se escuchó alguna vez, por dar un ejemplo, a "Alone” que hablaba sobre Renán y que se sorprendía del saber cuantioso y consentido de su introductor, el joven Abraham Valenzuela; o se escuchaba acaso la palabra tan vívida y concienzuda del profesor Zenteno A., disertando en un ciclo de conferencias sobre la "Adolescencia".

Nosotros, los que entonces éramos alumnos, sentíamos con particular intensidad lo que había de decoro y dignidad espiritual en estos ejercicios de alta cultura y en esta comunidad viva entre liceo $\mathrm{y}$ ambiente.

Ese mismo ímpetu llevó al Rector a reclamar para Concepción la insólita categoría de sede del bachillerato que, por definición, correspondía a la Universidad de Chile sin que entonces se viera por dónde aquella institución podía actuar fuera de su domicilio en la capital de la república. Pero debió ser tamaño el prestigio del establecimiento o, mejor, del Rector de ese establecimiento que le fue concedido el don. $\mathrm{Y}$ en tan alta jerarquía que ha sido la única sede 
no santiaguina del bachillerato que se autoadministró: fueron los profesores del Liceo de Concepción los que asumieron la tarea de tomar las pruebas, sin la presencia de delegados de Sanitago. Indice altísimo de prestigio docente.

Cuando a don Enrique se le pregunta por las cosas de más alto vuelo que se realizaron durante su gestión rectoral en el liceo recuerda dos: la institución de la sede excéntrica del bachillerato, de que acabamos de hablar, y la institución de las "Fiestas de la Primavera”. Y de éstas recuerda sobre todo el escándalo que la iniciativa suscitó en los medios tradicionalistas de la ciudad. Pareció una irreverencia. ¡Cómo! ¿Había el liceo de auspiciar fiestas en rigor circenses, propicias a toda desmesura y esencialmente ajenas a la "compostura” y dignidad docentes? ¡Batalla, triunfo y apoteosis!

Pero era el sueño universitario lo que desde el primer instante de su aposentamiento en Concepción trabajó el espíritu del Rector de las grandes realizaciones.

Viaje de estudio a los Estados Unidos de Norteamérica.-El señor Rector del Liceo de Concepción, positivista y evolucionista confeso en los años de su iniciación pedagógica en Chillán, convertido en Rector del Liceo de Talca, en medio de luchas y de preocupaciones obsesionantes, tiene tiempo -o acaso como antídoto para esas preocupaciones lo forja- para leer a pensadores estadounidenses de que entonces no había noticia en el país: Lester Ward y William James. Sobre el primero de ellos lee un conferencia en 1907; sobre el último, una en 1908. Una y otra aparecen en su libro primigenio de glosas filosóficas: Filosofía americana (1912).

En el transcurso de la dura batalla en que se vio envuelto su amigo Alejandro Venegas en Talca - como antes dijimos- se alejó él en viaje a Europa. Entonces se interesó por Bergson: "conversando en 1912 en Berlín con el ilustre profesor de su Universidad, Jorge Simmel, me dijo éste que Bergson era el más grande filósofo de nuestra época. Sorprendido y espoleado por esta apreciación, de regreso a Chile, me puse de nuevo a estudiarlo con ahinco, animado 
esta vez del propósito firme de llegar a penetrar su pensamiento. Fruto de tal empeño fueron tres conferencias que a fines de 1914 dicté en esta Universidad (de Chile). Mis conferencias salieron a luz poco después en un folleto, bajo el título La filosofía de Bergson".

Por otra parte, había dejado constancia de sus experiencias pedagógicas en Alemania en el libro Educación contemporánea.

De tal modo que el Rector del Liceo de Concepción tenía a su haber un patrimonio apreciable de obras de valor cultural excepcional en el orden pedagógico y en el orden filosófico.

No extraña, por lo tanto, que hacia principios de 1918 emprendiera nuevo viaje al extranjero, en misión del gobierno, para estudiar la educación en los Estados Unidos de Norteamérica.

Recorre de este a oeste el país inmenso. Ve y admira los campos mejor cultivados y las ciudades más industrializadas del mundo. Soporta la atmósfera asfixiante de Chicago bajo un cielo horrible, en medio de un bosque de chimeneas, una atroz baraúnda y una lluvia de hollín en contraste con la limpieza, el orden y la elegancia de Boston, la belleza y suntuosidad de Washington y el claro cielo de Nueva York.

Visita las Universidades de California, Lelan Stanford Junior de Wisconsin, las de Chicago, North Wester, Columbia, Yale, Filadelfia, Princeton y Harvard. Admira a veces la magnificencia de los edificios o la riqueza de bibliotecas y laboratorios; otras veces el encanto del paisaje, el hechizo del ambiente.

Departe en Berkeley con Dewey, que ya ha publicado La inteltgencia creadora, sobre cuestiones sociológicas y sobre las dos Américas vistas comparativamente.

$\mathrm{Y}$ al concluir su viaje tiene una idea bastante completa de los Estados Unidos de Norteamérica y bastante distinta de la que difundiera Rodó: país de las ciudades ciclópeas y de las industrias gigantescas, país mecanizado; pero también país de enormes poetas como Poe y Whitmann en lo presente, y grandes estadistas en lo pasado, como Lincoln y Washington. 
Entretanto la Universidad de Concepción había nacido.

"Vino (la Universidad de Concepción) a la existencia - decía don Enrique Molina al conmemorar los 25 años de vida de la institución- para satisfacer un anhelo sentido en esta ciudad desde los últimos decenios del ochocientos. Conmemoramos así la materialización de un largo ensueño.

En efecto, el Rector del Liceo de Concepción don Javier del Viliar, durante los años 1888-1891, personalidad excepcionalmente interesante, reclamando mejoras a su juicio indispensables, decia: "Voy más lejos aún. Juzgo que ha sonado la hora de descentralizar la instrucción superior. Juzgo que no sólo la zona central del país sino también la boreal y la austral tienen ya derecho legítimo a que existan en su seno establecimientos idénticos al Instituto Nacional con las dos secciones que éste abraza, secundaria y superior, y aún si ello pudiera ser con una Universidad propia. La nación ha avanzado lo bastante para que no sólo la capital sea el centro privilegiado dispensador de los conocimientos que han de formar los abogados, médicos, ingenieros, etc., constriñéndose a millares de aspirantes a alguno de estos títulos a atravesar año a año medio país para obtenerlos".

Sin embargo, desde el lejano año de 1865 - es decir, en tiempos de don José Joaquín Pérez (1861-1871)—, existía un Curso de Leyes anexo al Liceo de Hombres de Concepción. "La existencia de la Escuela de Derecho - decía don Enrique en 1929- había colocado desde hace más de sesenta años algunas palmas universitarias en el escudo de esta ciudad".

"Recuerdo que en marzo de 1917 solicité, en una entrevista, del Presidente de la República, señor Juan Luis Sanfuentes, que fundara la Universidad de Concepción.

"Por ese tiempo no concebíamos - y así fue durante dos años más- que la Universidad pudiera existir de otra manera que funciada por el Estado. Las circunstancias, que debemos saber aprove- 
char y que son a veces las conductoras de los hombres, iban a hacer que nuestros anhelos se realizaran de otra manera.

"El Presidente acogió el proyecto con muy buena voluntad. Pero las eternas dificultades financieras le impidieron tomarlo inmediatamente como un propósito del gobierno.

"Mas la idea lanzada en aquella entrevista cayó en Concepción cual chispa incendiaria de ánimos, y el civismo de los penquistas se alzó para luchar por la consecución del Instituto de Estudios Superiores con que se venía soñando desde hacía tanto tiempo.

"Se organizó entonces el Comité pro Universidad y Hospita! Clínico de Cozcepción.

"Después de diversas gestiones, el Comité se convenció de que el gobierno no crearía quién sabe en cuánto tiempo la Universidad.

"No eran sólo penurias financieras las que lo impedían. Había también de por medio - hay que reconocerlo- rivalidades y temores políticos y sectarios. Y no faltaba tampoco la menguada intriga de algún corazón pequeño. No faltó aquí mismo quien sembrara la desconfianza diciendo que el nuevo establecimiento iba a ser un foco de maximalistas, nombre con que se designaba por aque'los días a los revolucionarios rusos antes de llamarlos bolcheviques.

"Un diputado de esta región ¡cómo creerlo! fue personalmente a notificar al Ministro de Educación de que atacaría al gobierno si éste presentaba a las Cámaras un proyecto sobre creación de la Universidad de Concepción.

"El proyecto fue presentado por un grupo de parlamentarios. Y otro diputado para contrarrestario, apareció en el hemiciclo con la moción de crear las Universidades de Antofagasta, La Serena, Valparaíso, Talca, Temuco, Valdivia, Osorno y no recuerdo cuantos pueblos más.

"Era el ridículo y el proyecto quedó sepultado.

"Pero el comité no se dio por vencido y en enero de 1919 resolvió por su cuenta y riesgo que, al iniciarse el año escolar, se abriría la Universidad con las Escuelas de Ingeniería Química, Farmacia, Dentística, Pedagogía con curso de inglés y matemáticas superiores. 
"El Comité acordó obtener que los cursos de matemáticas y pedagogía pudieran funcionar en el Liceo de Hombres y el de dentística en el Hospital. Acordó asimismo que la mesa tomara en arriendo un local adecuado para las Escuelas de Farmacia e Ingeniería.

"No había, pues, ningún edificio universitario.

"Tampoco había presupuesto para sueldos.

"Estaba presente en esta sesión en que se tomaron tan temerarios y trascendentales acuerdos, el doctor Virginio Gómez, que la presidió en su calidad de vicepresidente del Comité".

La magna creación cuenta cerca de cuatro décadas de vigorosa existencia: 1919-1957. Procuremos cifrar su peripecia en términos esquemáticos porque se advierte la trascendencia de la mayor hazaña de su inspirador, fundador y Presidente y Rector Vitalicio, don Enrique Molina.

Cuenta inicialmente con una sola Facultad llamada de Ciencias que ahora se halla diversificada en seis: de Filosofía y Educación; de Ciencias Jurídicas y Sociales; de Ciencias Físicas y Matemáticas; de Medicina, de Química y Farmacia y de Odontología.

Aspira a la satisfacción de tres objetos diferentes que concurren en una sola finalidad coherente: la de forjar una disciplina científica autónoma; la de formar una pléyade de profesionales doctos y responsables; la de entonar la cultura nacional.

Al primer objeto responde la serie de sus Institutos de Investigación: el de Física y Matemáticas; los de Histología y Embriología; de Anatomía; de Anatomía Patológica; de Fisiología; de Biología y Parasitología; de Bacteriología e Inmunología; el de Odontología; los de Farmacia; Botánica y Farmacognosia; Química General, Química Orgánica. A los que se añaden el Seminario de Derecho Privado, el Seminario de Derecho Público y el Seminario de Ciencias Económicas.

Al segundo objeto responde la serie de sus Escuelas Profesionales Superiores: la Escuela de Educación, la de Ciencias Jurídicas y Sociales; la de Medicina; la Dental, la de Química y Farmacia.

Al último objeto, responde la organización de la Extensión Uni- 
versitaria de que son instrumentos: la revista "Atenea", fundada en 1924, una "Revista de Derecho" y un "Boletín de Biología"; la tribuna universitaria por la que desfilan cientistas, artistas y pensadores nacionales y extranjeros que la Universidad invita a dar lecciones públicas en su Sala de Conferencias y el Teatro de la Universidad, que acoge las manifestaciones del cine, del teatro y de la música.

La Universidad - que no cuenta aunque anhela una Facultad de Agronomía - dispone de dos fundos aledaños a la ciudad, el "Andalién" y el "Bellavista" y un Jardín de Cultivo de Plantas Medicinales. $\mathrm{Y}$ ha montado una Oficina de Informaciones y de Experimentación Agrícolas, que constantemente ofrece cursos breves en la ciudad y fuera de ella a los agricultores, y organiza exposiciones avícolas y apícolas.

Finalmente, su Biblioteca Central $-50,000$ volúmenes- y la serie de sus bibliotecas especializadas - de que están dotados escuelas e institutos- constituye un repertorio de instrumentos de cultura útiles a la pluralidad de fines que la Universidad tiene en vista existencialmente.

La Universidad posee 45 hectáreas de terreno en la linde de la ciudad misma, circundadas de colinas cubiertas de pinares. $Y$ en ese emplazamiento ideal se alzan los monumentos arquitectónicos en que se alojan escuelas e institutos.

Y ahí también se alza, como una de esas realizaciones arquitectónicas integrantes del "corpus" universitario, el primero de la serie de hogares estudiantiles que la Universidad se siente obligada a ofrecer a los estudiantes: habitaciones individuales, salas de estudio y de recreación, bibliotecas, etc.

Junto al Hogar, la Casa del Deporte, gimnasio cerrado -el mejor del país- con moderna utilería para ejercicios físicos y juegos de básquetbol.

$Y$ en medio de aquellos campos de esmeralda se alza -índice de alta idealidad - el campanil, caro al alma del Rector, desde cuya plataforma superior -encumbrada en 42 y medio metros- el espectador avizora la ciudad y sus contornos. 
De ese modo, la Universidad traduce su preocupación por la vida total del estudiante que busca su amparo en la hora de formación: educación intelectual, sí; pero también y fundamentalmente guarda de la salud del cuerpo y del alma, física, intelectual, ética y estética.

¿De dónde provienen las rentas que permiten estos lujos del espíritu junto a estas fuentes de energía? De aquella benemérita, y en su hora pecaminosa Lotería Nacional, que renta unos 50 millones de pesos anuales. (derramándose el resto - 25 millones - en fecundar otras áreas de la cultura o de la salubridad nacionales). Suma en rigor exigua para necesidades, como es natural, crecientes.

¿Cuánto han llegado a valer los bienes que la Universidad - admirable conservadora de sus bienes - ha logrado acaudalar? Han llegado a valer unos 180,000 millones en inmuebles y unos 20,000 en bienes muebles.

Esta es la obra que don Enrique Molina ha presidido - vivo campanil- durante los últimos cuarenta años de su existencia: protagonista y símbolo.

Vengamos ahora a las creaciones de su espíritu, en el orden de las letras, a sus libros.

Y digamos desde luego que el altísimo señor que él es, prefiere con mucho la hazaña personalísima de sus creaciones literarias a la hazaña compartida de su capitanía universitaria.

El origen y el método de la creación molinesca.-El profesor de Historia don Enrique Molina, se ha propuesto enseñar conforme a un credo que sea auténticamente suyo, que traduzca su personalísima manera de sentir la vida en su doble dimensión individual y social. $Y$ ésa su manera personal de sentir condice con el ambiente espiritual de su tiempo en la hora de su "formación": último cuarto del siglo XIX. El profesor Molina es un apasionado de la Ciencia, 
entendiendo por tal la ciencia positivista de Comte: Darwin y Spencer son sus guías tutelares en la concepción del hombre y en la concepción de la educación.

Durante un instante de su vida pertenece "a esa generación de hombres progresistas de nuestro país que en los años del siglo pasado, entre el 60 y el 90 , creían que el positivismo significaba el ápice definitivo del pensamiento humano, más allá del cual no había que buscar nada ni inquietarse por nada en materia de temas transcendentales".

Pero -y esto es lo excepcional y valioso en él- don Enrique supera esa primitiva posición doctrinaria.

Rara avis.-Cuando el profesor don Pedro León Loyola - nuestro profesor de Filosofía en la Universidad- fue recibido en calidad de Miembro Académico por la Facultad de Filosofía y Educación, que lo había contado como uno de sus más destacados miembros docentes, el profesor don Roberto Munizaga, que lo recibía, trazó un cuadro de los estudios de Filosofía en Chile en el momento en que el joven profesor Loyola había asumido la cátedra en el Instituto Pedagógico, en el año 1918.

"Naturalmente - dijo- su enseñanza iba a desenvolverse en la atmósfera filosófica de la primera década del siglo que, lo mismo entre nosotros que en Europa, podía resumirse en las tres posiciones radicales de Cientismo, Positivismo y Relativismo, con sus conocidas tesis sobre la estructura del Universo, el conocimiento y los valores. La influencia de Schneider se había prodigado en Cientismo, según el modelo de su maestro Haeckel y de Taine; la obra de don Valentín Letelier destilaba Positivismo, según Comte y Spencer; el doctor Guillermo Mann aclimataba la Psicología Experimental de Wundt. Y don Enrique Molina - rara avis- había comenzado a explorar algunos dominios de la Filosofía americana".

Rara avis es una feliz designación para la figura de don Enrique Molina en cuanto a su quehacer filosófico de primera hora: ser extraño que vuela hacia regiones ignotas. 
En efecto, las corrientes filosóficas de que Chile estuvo consciente $y$, en alguna medida, atento, provinieron siempre de Europa, cuna de la cultura de Occidente. Don Enrique Molina, sin embargo, atisbaba tempranamente nuevos valores emergentes en la gran nación del norte de América tenida hasta entonces por bárbara y que logrará decir su palabra en el orden espiritual con tanta fortuna que los propios europeos atiendan a su decir y, en considerable medida, por un instante al menos, se le subordinen.

Don Enrique Molina fue, respecto de estas gentes norteñas, profeta y augur entre nosotros.

Dos pensadores penetran en el área de sus preocupaciones entre 1907-1908: Ward y James, para tomar del uno las doctrinas del "meliorismo" - término medio entre pesimismo y optimismo- y de la sociocracia - predominio de los intereses colectivos en la organización social subordinándoles los intereses meramente individuales; y para tomar del último la postura que identifica la verdad con lo conducente a la acción sólo con respecto al mundo metafísico. Y ello, porque, en verdad, como sostiene Claudio Rosales, "leemos para encontrar la comprobación de nuestra verdad y no para aprender". Don Enrique Molina sintió que Ward era alma gemela de la suya y que él mismo era un "meliorista" a nativitate. En cambio, el suponer que ia verdad objetiva quede fuera de nuestras posibilidades de conocer y que hayamos de tener por verdadero lo que conduzca a más vida, le pareció, con razón, que importaba abandonar la fe en la posible certeza para abandonarse a un relativismo inconsistente $y$, en rigor, desesperado. Y la doctrina le parece buena precisamente ahí donde el imperio de la razón humana no halla asidero bastante para hacer pie firme en la investigación de la verdad: en el orden metafísico. En verdad, lo considera bueno para un terreno que, en ese momento de su vida, tenía escasa significación para él.

La sugestión de Simmel.-Hacia 1910 el catador de novedades espirituales había dado con la Filosofía de Bergson, cuya obra Los datos inmediatos de la conciencia, aparece en 1888. 
Lee entonces unas cien páginas de La evolución creadora, pero se da cuenta "de que no iba penetrando en la doctrina sustancial del autor". "Y dejé por el momento el libro".

Sin embargo, de paso en Berlín conversa con Simmel, profesor en la Universidad de esa ciudad, quien le asegura que "Bergson era el más grande filósofo de nuestra época. Sorprendido y espoleado - confiesa- por esta apreciación, de regreso a Chile, me puse de nuevo a estudiarlo con ahinco, animado esta vez del propósito firme de llegar a penetrar en su pensamiento".

Lo leyó. Creyó entenderlo. Y se dispuso a darlo a conocer a los demás. Para ese efecto dio tres conferencia en la Universidad en 1914 en que estudió las concepciones bergsonianas de la libertad, de' tiempo, del espíritu y de la vida.

"No dejé de manifestar mi disconformidad, en parte, con el espíritu bergsoniano. Sobre la hipótesis de Bergson de la existencia de un impulso vital original (élan vital), teoría vitalista sobre el origen de la vida, decía que era un Deus ex machina que no explicaba nada. "Debo confesar que esta crítica me parece ahora injustificada: El misterio del comienzo de la vida se yergue siempre ante nosotros indescifrable. El paso de la Nada a la Existencia no puede darlo el pensamiento sino en alas de suposiciones de su imaginación creadora. Si no aceptamos un Dios, Supremo Hacedor del Ser y de la Vida y aceptamos la idea spinoziana de un Ser eterno e infinito existente por sí mismo, tenemos que suponer en El las potencialidades de la Vida y del Espíritu".

Por la misma época lee a Guyau y, segunda vez, siente que el escritor es una alma afín a la suya. Conviene en que sus disquisiciones no son todo lo rigurosas que pudieran. Pero no se trata de rigor ni de convicción intelectual. Se trata de "simpatía", de análogos modos de sentir la vida y de colocarse frente a ella.

Sus estudios sobre Bergson y los sobre Guyau aparecen juntos en 1925.

La sugestión de Keyserling.-El conde-filósofo, fundador de la 13-Atenea N.0 376 
Escuela de Darmstadt, visitó Chile y dio conferencias en el Teatro Municipal de Santiago, en 1929, sobre nuestra cultura en el momento actual y sobre la "necesidad de darle un claro contenido espiritual".

Descubrió don Enrique Molina que las ideas del filósofo alemán se asemejaban a las suyas. "Consideré conveniente no silenciar mi pensamiento por más tiempo y pocos meses después de Keyserling dí a mi vez en esta Universidad tres conferencias sobre los asuntos indicados".

"Ampliadas con nuevos estudios y reflexiones se convirtieron en un Curso de Filosofía que ofrecí en la Universidad de Concepción en 1935 y que ha sido publicado en un volumen con el título $\mathrm{De}$ lo espiritual en la vida humana".

La sugestión de Nietzsche.- "Coincidente casi con el centenario de Nietzsche (1944) hice un curso sobre este filósofo.

"Simpatizando con su personalidad, tan austera como sufriente y doliente, no pude, sin embargo, dejar de poner en claro sus contradicciones, su egolatría, y de criticar la mayor parte de sus doctrinas: el superhombre, la voluntad de poder, el eterno retorno, el cu'to de Dionysos.

"En este último punto, sostengo que el camino de perfección del hombre se halla en el paso de Dionysos a Apolo, en el dominio de sí mismo, en el triunfo de la razón sobre el instinto, en lo que éste no tenga de indispensable para la vida.

"Este curso se halla contenido en mi libro Nietzsche, dionisíaco $y$ asceta".

La sugestión de Ferrater Mora.-El joven filósofo español, durante su permanencia en Chile -1944-1947-, fue profesor del Instituto Pedagógico. Residente en los Estados Unidos público una obra, El sentido de la muerte, 1949.

Ferrater, estrictamente español, sostiene que la vida es una preparación para la muerte. Don Enrique Molina, radicalmente meliorista, vitalista y apolíneo, salta al palenque para desdecir al español, 
sosteniendo que la vida es un ejercicio constante de superación en gracia de la vida misma.

Y Bazán comenta: "Al escuchar estas dos voces ungidas de opuestos sentimientos, un tanto lúgubre la del filósofo español, alegre la del Rector de la Universidad de Concepción, se piensa que tal vez la manera de ver y de sentir el mundo no dependen de las ideas sino del temperamento de cada uno".

La sugestión de Descartes.-Con ocasión da la semana cartesiana, don Enrique Molina, en Leyendo de nuevo a Descartes, lo desvalora como precursor del pensamiento en la Filosofía Moderna, rebate algunas observaciones de García Morente (en un libro destinado a una consideración panorámica del pensamiento filosófico de Occidente en general) y, finalmente, corrige a Descartes diciendo que la fórmula "Pienso, luego existo", pudo venturosamente completarse diciendo "Pienso, luego existo, y el Ser existe", con lo que, a su juicio, se habrían evitado muchos quebraderos de cabeza sobrevinientes a causa de no haber declarado desde luego la existencia del Ser.

Todos estos casos ilustran bien sobre el origen y método del filosofar de don Enrique Molina.

Don Enrique Molina sale a caza de novedades por el ancho mundo. Descubre a pensadores del buen sentido, tipo Ward, o a poetas metafísicos, tipo Guyau, y, en virtud de la afinidad espiritual que con ellos siente, les concede su amor. Cuestión afectiva, problema de simpatía.

Lee a Bergson y siente que resbala, que no le dice nada. Y lo deja. Pero Simmel, en Berlín, le cuenta que es lo más grande que el siglo ha producido. $\mathrm{Y}$ se obliga a releerlo y a entenderlo.

$\mathrm{Y}$ entonces, sin dilación, entrega el fruto de sus meditaciones al público.

Porque desde la primera hora de su juventud decidió ser guía y conductor de su grey nacional: forjarse una concepción de las cosas y del mundo y darla a conocer. 
Ocurre que lo que en 1914 dijo de Bergson, le parece una demasía en 1950. Pero ello no ha obstado para que en la primera hora declarara todo su pensamiento sin atenuantes ni es óbice para que sin atenuantes se corrija, cuarenta años después. Su misión es ser voz de su pueblo, intrépidamente.

Escucha a Keyserling. $\mathrm{Y}$ halla que el pensamiento del germano no es tan disímil del suyo. Y tras el conde-filósofo ocupa la tribuna el Rector-filósofo y habla sobre los mismos temas. Se siente que le habría gustado hacer suya la fórmula de la Universidad de México: "Por mi raza hablará el espíritu".

En este caso, el proceso adquiere una segunda instancia: de la mera forma de la conferencia o ciclo de conferencias, ensanchada la materia con meditaciones nuevas: variaciones sobre el mismo tema, se origina un curso público en su cátedra de Filosofía de la Universidad de Concepción, cuyos auditores no son estudiantes universitarios sino ese público especial que, a las 7 de la tarde, ocurre a escuchar conferencias.

Y tras esta segunda instancia reformadora, adviene el libro que se llamará De lo espiritual en la vida humana, y que pretende ser la primera de sus Confesiones filosóficas, es decir, la primera exposición del florilegio filosófico de su consentimiento.

En plena posesión de lo que es su íntimo consentimiento - don Enrique Molina trabaja por intuiciones emotivas- estudia a Nietzsche, ron ocasión del centenario de su nacimiento (1844-1944).

Habiendo sido Nietzsche un hombre de un pensamiento fulgurante, desmesurado y contradictorio, pero lleno de atisbos genialcs, don Enrique Molina aplica su buen sentido y pone sistemáticamente de relieve las incoherencias de bulto del pensador-poeta germano respecto de ese nivel medio de pensamiento.

Sus pensamientos sobre la incoherencia nietzscheana se organizan bajo la consabida forma del curso vesperal en su aula universitaria y, seguidamente, se transforman en el correspondiente libro: Nietzsche, dionisíaco y asceta. , 
Caso análogo ocurre con Ferrater. Publica ya en los Estados Unidos una obra, Dei sentido de la muerte; don Enrique siente que esos pensamientos ensombrecen el vivir que él siente diáfano, eglógico. Entonces, con ocasión del primer aniversario de la fundación de la Sociedad de Filosofía, que preside, coge a Ferrater y vuelve las proposiciones del español de afirmativas en negativas: ¿La vida es una preparación para la muerte? No. Es un ejercicio espiritual de superación en gracia de la vida misma. Bazán entonces piensa: Parece que esto de pensar es más bien cuestión de sentir.

La misma Sociedad de Filosofía prepara un homenaje a Descartes en el cuarto centenario de su fallecimiento. $Y$ el presidente de la Sociedad, declara que no le parece tan excepcional la figura del pensador francés ni fundada su reputación de fundador de la Filoso fía Moderna. Y luego hace el elogio de Spinoza, que le parece mucho más convincente. Finalmente, declara qué fue lo que Descartes debió haber dicho para haberse y habernos cvitado tanto problema subsiguiente a su proposición Cogito ergo sum. Ello fue añadir "Y el Ser existe".

Don Enrique Molina es, en estos casos, maravillosamente intrépido.

En resumen, don Enrique Molina opera desde su corazón. Y conforme a sus dictados, enfrenta a los hombres de pensamiento de varias naciones y de varias altitudes espirituales y los mide conforme a su simpatía y conforme a su nivel de bon sens.

Por eso dice Claudio Rosales, al recibirlo como Mienıbro Académico de la Facultad de Filosofía de la Universidad de Chile, "Su virtud cardinal es, sin duda, la de ser profesor. Las demás facetas de su personalidad son aspectos de esa virtud". Y al término de ese discurso: "La figura del señor Molina emerge en cuanto pensador"... "Sin embargo, la autenticidad de su prestigio dentro del país, no debe buscarse en lo que él tiene de filósofo o formador de almas. Vale más por su hombría de bien y su sentido de la responsabilidad".

Las tres confesiones filosóficas.—¿Qué son las Confesiones Filo- 
sóficas de don Enrique? Son exposiciones de las proposiciones que él considera valederas en el ancho campo de la Filosofía y a lo largo de todo el desarrollo de la cultura de Occidente. Representan el zumo, la esencia de las esencias filosóficas. Es un florilegio de proposiciones fundamentales: su "credo".

El las ha escogido en la selva de pensamientos que la Filosofía de Occidente nos ofrece. Es el seleccionador.

Las confesiones filosóficas de don Enrique son tres. Pero sólo la segunda - que es la más solemne por la ocasión en que se formula- lleva precisamente ese nombre. La primera es su obra entera llamada De lo espiritual en la vida humana. Y la última es la Tragedia y realización del espíritu. El estima que las tres se complementan recíprocamente.

La raíz metafísica.-Estas Confesiones Filosóficas inciden esencialmente en el orden de los problemas metafísicos. Y ello es de notar puesto que los comienzos de la vida intelectual del protagonista de esta aventura, se cifraron en el orden de las Ciencias Positivas y de la consiguiente postergación de la dimensión metafísica de la realidad que, por inaccesible a las posibilidades del pensamiento humano, ha de ser desconsiderada.

La página liminar de la obra dice así:

"Si los hombres pudieran vivir guiados por las luces de un deísmo definitivo, habrían resuelto uno de sus problemas más inquietantes. Mientras esto no ocurra, viviremos más o menos resignados, más o menos desolados; atolondrándose unos en el tráfago de las excitaciones, agitaciones y cambios que ofrece la vida y dándole a todo esto, en el mejor de los casos, la sazón cálida de algún amor; otros buscando siempre un sentido en medio de la fluencia de las cosas, buscando con inquietud atormentada o con serenidad estoica el hilo de oro de lo divino, lo espiritual y lo eterno que nos conduzca a través del laberinto. Suele haber un vacío opresor en el alma del hombre que no encuentra a la vida un sentido trascendente. $\mathrm{Y}$ sigue buscando". 
"Dios a la vista" pudiera haber sido el título de esa obra, como lo fue de uno de los ensayos orteguianos de El espectador. Aquí se habla de inquietud, desolación, tormento, vacío frente a excitación, agitación, cambio, fluencia de las cosas, tráfago y atolondramiento. Por lo que no ha de extrañar que la "tercera confesión" se llame precisamente Tragedia y realización del espiritu y que en ella se lea:

"En esta breve disertación, tras de resumir los conceptos esenciales de ambas confesiones, voy a tratar de completarlas, mostrando que a la realización del espíritu la precede siempre una etapa dolorosa, a veces superada, a veces no"... o sea - añadirá más adelante- que ella se lleva a cabo en un proceso cuyo primer término es una Tragedia".

Al mediar el año 1949 y con ocasión del primer aniversario de la Sociedad de Filosofía, don Enrique se enfrenta con la Muerte y su sentido en la forma de un ensayo de Ferrater Mora. Don Enrique lo encuentra "negativo". En rigor, teme.

"No hay temas más vastos para nuestro espíritu. Y son insolubles en cuanto no existe solución que pueda acallar el ansia, a veces angustiosa, que es la esencia de la vida, ni acallar las preocupaciones de la muerte".

La esencia de la vida es el ansia, a veces angustiosa, dirá ahora don Enrique que, con ocasión de su recepción en la Facultad de Filosofía en la Universidad de Chile, había lucido, en noviembre de 1941, su conocimiento y prolongado trato con Heidegger, en quien hallará esa expresión alemana (más incisiva que la española correspondiente) Angst. El tema de su ensayo oscila, pues, entre el ansia angustiosa de la vida y las preocupaciones de la muerte. Don Enrique se opone a Ferrater asomándose a "estos abismos para mirar con nuestros débiles ojos hasta donde alcancemos". Y cuando se opone "sin agotar el tema" ¿qué hace sino defenderse del ansia angustiosa de la vida que desemboca en la muerte?

En la hora del alba don Enrique fue un gozoso catador de la existencia, un hombre pour qui le monde extérieur existe y existe precisamente para sentar el pie en él señorialmente y gozarlo. En la 
hora del ocaso, está tratando de penetrar, con débiles ojos, el abismo angustioso, asomado a la muerte, negándola para no temerla...

Tampoco en este momẹto piensa con pensar filosófico, fríamente racional. Don Enrique, fiel a su destino, siente y traduce su sentir en proposiciones que aún quisiera vestir de serenidad y decorar con una sonrisa y denunciar con una profesión de fe en lo cierto que anhelamos poseer.

No hace falta detenerse demasiado en el correr de sus proposiciones que orillan los grandes temas. Pero hace falta hacer notar cómo este hombre cabal recorrió, en su luenga y feliz existencia, todas las etapas y fue siempre fiel al destino de cada hora. $\mathrm{Y}$ vino a parar de positivista y cientista a outrance en metafísico y ontólogo, azotado por ráfagas de divinidad.

Convendrá, sin embargo, dejar constancia de las proposiciones fundamentales que constituyen su "Credo" filosófico y de que hizo mención en su Confesión Filosófica el 11 de noviembre de 1941, con ocasión de su recepción como Miembro Académico de la Facultad de Filosofía de la Universidad de Chile.

1. Lo esencial de la Filosofía lo encontramos en las disciplinas que nos conducen a obtener una intuición del Ser, a tentar una interpretación suya y luego a definir nuestra actitud ante él.

2. Aristóteles ha dicho que a los hombres los estimuló a filosofar la admiración. Sí; pero además el dolor y el error.

La limitación de nuestras satisfacciones y la limitación del tiempo que conduce a la muerte han sido también maestros de Filosofía de los hombres.

Así angustiados lanzamos nuestras interrogaciones al mundo que nos rodea para concluir casi siempre después de nuestro periplo por caer de bruces deslumbrados ante el misterio.

Pero nos es dado también que la angustia que nos invitó a filosofar se convierta en serenidad.

3. ¿Será posible desahuciar a la Metafísica?

¿Será posible reducir la Filosofía a una ciencia en sentido estricto? 
La necesidad de la Metafísica y la imposibilidad de suprimirla se prueba con el hecho sencillo de que hay una región en que no cabe sino ella y de la cual no se puede prescindir.

Maravillosos son, sin duda, los progresos de las ciencias; pero éstas no bastan a satisfacer las ansias ni a responder a todas las interrogaciones del espíritu humano.

4. Nuestros momentos de mayor plenitud psíquica se substraen sutilmente a todo cálculo y a toda expresión en términos precisos. ¿Cómo conocer el amor, el entusiasmo, la inspiración, la gratitud, la satisfacción de hacer el bien, el placer, también el dolor, sino experimentándolo? El alma sabe de estas cosas, no por medio de números sino siendo ella misma a la vez surtidor y objeto que se baña en la linfa de su fuente.

5. Así también los problemas filosóficos constituyen un mundo que, aun sin lograr en su indagación conclusiones exentas de dudas, con adentrarnos y permanecer en ellos nos permiten vivencias que, por otros lados, sólo se alcanzan tal vez en las formas superiores de la Religión y del Arte. Nos permiten acercarnos a vislumbres de lo trascendente, intuir por momentos la esencia de lo eterno.

6. Las cosas son doblemente misteriosas: por la condición obscura de su razón última y porque lo que nos es dado saber lo sabemos con signos imperfectos.

Las evidencias que alcanzamos gracias a la intuición inmediata de verdades a priori y a la comprobación metódica de las a posteriori nos garantizan la posibilidad de llegar a certidumbres aceptables.

7. Cabe conferir a la conciencia categoría de algo absoluto en el orden gnoseológico, como última instancia de nuestro conocer; en el orden ético como fuente de inspiración y tribunal inapelable de nuestra conducta. Pero no en el orden ontológico, en el del Ser, donde si bien sus orígenes en potencia pueden confundirse con éste, no así su clara aparición que, como queda dicho, es posterior a la de la Vida.

8. Lo desconocido nos rodea. La angustia es el temor a lo desconocido. Tengo la clara intuición de que mi existir es estar en el 
Ser Universal. El aliento vital se sobrepone a la angustia cuando es suficientemente poderoso o, si queréis, sano. La vida es ilusión obstinada, afirmación continua de lo trascendente.

9. El Ser no se define: se percibe, se siente, se intuye.

Comprende todo lo que abrazan las antenas captadoras de nuestro entendimiento y el Espíritu con todas sus modalidades ideales, que le es inmanente.

10. Con el ilustre griego - Parménides - pensamos que el Ser es único, infinito y eterno. $\mathrm{Y}$ con el genial holandés - Spinoza- que lo que hemos dicho de que sea absoluto se refiere a sus sustancias mientras que sus modos son contingentes.

11. El razonamiento cartesiano "para ser completo, debe formularse en mi entender de la siguiente manera: "Pienso, luego existo. Y el Ser existe". Al filósofo le es absolutamente imposible concebir su pensamiento como del todo solo en el mundo. Suponiendo que esto fuera hacedero, la rectificación que proponemos quedaría siempre en pie en los términos siguientes: "Pienso, luego existo. Y el Ser existe. Yo soy el Ser".

Lo Absoluto queda integrado por el Sujeto y el Objeto en una entidad que es armonía de estos contrarios.

12. El Ser se ha desdoblado. Y lo encontramos contemplándose a sí mismo por medio de la Razón, de nuestra razón humana.

Aunque Ser y Razón no son coincidentes, encontrándose la Razón en potencia en el Ser, formamos parte de él, estamos en él, vamos con él. Es a la vez inmanente y trascendente a nosotros.

La muerte es un cambio de formas en el Ser.

El amor también lo es, como propulsión íntima de sus movimientos.

La muerte es una consecuencia necesaria del amor en cuanto condición ineludible para la existencia de nuevos seres.

El amor y la muerte son las fases de luz y de sombra del disco en que en el plano de la vỉda gira el Ser en su afán ingénito de conservación. 
13. El Ser en sus modos contingentes existe en el espacio-tiempo. La temporalidad es de su esencia. La eternidad es la esencia del concepto de un momento que perdura sin cambiar. El tiempo es serie de momentos que cambian.

La eternidad es atributo del Ser puro substancial, que es lo mismo que Divinidad pura, o sea, misterio absoluto, si no salimos del plano de lo existencial.

14. Al pasar de los elementos físicos al organismo vital, la es tructura pone algo nuevo, que no se encontraba en los elementos integrantes. La trascendencia en este caso y la estructura es lo que Wundt y Lester Ward han llamado con términos muy expresivos, las síntesis creadoras de la Naturaleza: del quid misterioso no podemos librarnos.

15. El espíritu y la materia se hallan más unidos entre sí que dos hermanos siameses. Nos parece lo más plausible concebir ese espíritu como en potencia en la substancia del Ser. Y desdoblándose de él para realizarse a través del hombre.

16. Caracteriza al espíritu su inmanencia.

La acción sensitiva o perceptiva es trascendente: pasa del sujeto al objeto. La serie cuerpo físico, ser vivo, psique, espíritu muestra en este sentido el crecimiento del trascender. $\mathrm{Y}$ tal crecimiento llega al máximo posible en el espíritu.

El hombre es colaborador de la creación: existir en un Ser pleno de posibilidades es como estar en el seno de Dios.

17. Al revés de lo que pasa con la materia y la vida, sólo lo espiritual no se halla definitivamente hecho y espera para su alumbramiento que nosotros lo vayamos realizando.

La Razón, estructura superior del espíritu, se para sobrecogida ante el maravilloso y tormentoso existir humano.

La actitud filosófica en lo que respecta a la conducta la haría consistir en la serenidad y el equilibrio a que se llega por medio del cultivo de la Filosofía. Permite dar a las cosas su verdadera proporción y su perspectiva dentro de la comprensión de la universal.

18. Los valores superiores son esencias relativas al hombre, a la 
personalidad humana. En cuanto medidas de valoración poseen luz espiritual propia. Al exponer discursivamente su condición los valores toman la forma de conceptos cuya substancia se extrae de la apreciación de las cosas y de los hechos y en los cuales, por referirse a intereses profundamente vitales, existenciales, se infunde de manera inseparable el calor de los sentimientos.

19. La actitud filosófica es coincidente con el más perfecto ejercicio de la Libertad. Los motivos determinantes constituyen los antecedentes necesarios del acto en que la voluntad se decide por el que prefiere.

20. La actitud filosófica supone y supera las normas éticas y jurídicas. El filósofo hace de las normas que ha aceptado o que se ha dado, carne orgánica de su alma.

La actitud filosófica es de serenidad agonística, de una tranquila entereza de ánimo al frente de la lucha.

21. Hacer bien las cosas. Esta sencilla norma, practicada a fondo, puede operar una síntesis de la acción y de la contemplación. Me hallo tan penetrado de la santidad del trabajo honesto que estimo siempre respetable al que lo practica aunque por lo demás sea adocenado y padezca de miopía para ver más allá de los horizontes y de las apetencias de su rutina diaria.

22. Los hombres de ciencia no podrán decir nada jamás sobre un fin del espíritu, sobre si éste, tras la remota extinción de la vida en nuestro planeta, no surgirá en otros mundos donde encuentre los cuerpos vivos y las condiciones materiales que son necesarias para su florecimiento. $\mathrm{Y}$ así seguirá la aparición del espíritu que no es otra quizás la existencia misma de Dios.

Respecto de esta producción, la más cuidada de don Enrique, se han producido varios juicios, los más inclinados con exceso a la laudanza, y, por eso mismo, escasamente iluminadores:

El más autorizado de estos opinantes es el filósofo José Ferrater Mora que, esencialmente, dice:

Lo que se nos da en este discurso de recepción es una vida entera, una existencia que parece haber alcanzado su momento cul- 
minante. Cada una de sus palabras nos está diciendo que ha sido hondamente meditada, y muy en particular hondamente sentida.

La Confesión Filosófica de don Enrique Molina, es una piedra más sobre este glorioso edificio de la Filosofía Perenne que los hombres, desde los tiempos luminosos de Grecia, se han empeñado en zonstruir.

Don Enrique Molina ha vinculado la necesidad metafísica del hombre con la imperiosa necesidad de un saber riguroso. Esto le ha conducido a sostener el primado del Ser sobre la Conciencia. La clásica disyuntiva planteada por Fichte, constituye uno de los más dramáticos momentos en toda existencia filosófica. Cuando don Enrique Molina se decidió por el Ser, tuvo hecha ya la mitad de su confesión filosófica, la mitad de su vida.

Al lado del Ser encontró la Conciencia, encontró el Espíritu, que fue precisamente el que se había decidido.

Frente al Ser, que tiene la máxima existencia y la máxima posibilidad, pero que parece mostrarse inerte y poco impetuoso, el espíritu y la conciencia se orientan de un modo decisivo y orientan con ello al ser mismo hacia lo más alto que es posible alcanzar en este mundo: hacia el Valor.

Esta orientación hacia el Valor hace posible que concuerden un saber riguroso y una necesidad metafísica. Al reconocer el primado ontológico del Ser y el primado axiológico del Espíritu, la Confesión de Filosofía pudo formularse con la claridad, con el rigor y hasta con el entusiasmo con que don Enrique Molina la ha formulado.

Don Enrique Molina ha logrado en sesenca años de actividad ejemplar por la devoción, por el entusiasmo, por la perseverancia y por la fe que ha puesto en su obrar y por los altísimos valores en que supo inspirarse, que su nombre y el de su patria rayen muy en áto en la vida del Espíritu de que es confeso y esforzado paladín; ha logrado, además, lo que respecto de la historia de la cultura chi- 
lena se propuso en la primera hora de su juventud: hacer que la actividad filosófica, tan incierta en Chile, emergiese y que él fuera precisamente su campeón.

Esta es la hazaña de ese profesor de historia de la primera promoción del Instituto Pedagógico, hazaña que se materializa en su creación de la Universidad de Concepción, de que ha sido símbolo y espíritu al mismo tiempo.

Y esta doble hazaña teórico-práctica en el campo del Espíritu pone los inconmovibles cimientos de la estatua que Concepción le debe y que se alzará precisamente en aquella plazoleta de que arranca el campanil universitario. 